\title{
Exploring the relationship between Perceived Stress and Life Satisfaction among college students: the Indian context
}

\author{
Meghna Basu Thakur \\ Research Scholar, Department of Applied Psychology, University of Mumbai \\ E-mail-meghnabasuthakur1972@gmail.com \\ Corresponding Author - Meghna Basu Thakur
}

\begin{abstract}
Background: The current study attempted to examine the relationship between perceived stress and life satisfaction among college students in the Indian context and is based on prior research conducted on college students in Barbados.

Methodology: Sample comprised 50 undergraduate students who completed the following questionnaires: Perceived Stress Scale- 4 item version, Satisfaction with Life Scale (SWLS) and an adapted version of Chow's satisfaction with specific aspects of life scale. Data obtained from the participants were subjected to relevant statistical analyses.

Results: A significant negative correlation was obtained between perceived stress and life satisfaction (both generic and domain-specific). Findings obtained in the current study have been discussed in the light of existing literature.

Conclusion: The study has crucial implications for mental health professionals to design appropriate psychosocial interventions for the target population.
\end{abstract}

Key words: perceived stress, life satisfaction, students, mental health.

(Paper received $-10^{\text {th }}$ September 2017, Peer review completed $-30^{\text {th }}$ September 2017)

(Accepted $-6^{\text {th }}$ October 2017)

\section{INTRODUCTION}

College students are prone to experiencing higher levels of stress [1]. This is because they face multiple challenges during college life with respect to maintaining excellent academic record, increased academic responsibilities, making adjustments to the new environment [2-3]. When understanding the phenomenon of stress, it is also important to comprehend the concept of stressor. It is defined as anything "that which produces stress" [4]. Stressors impacting college students can be grouped into four categories: academic, financial, time or health related, and self-imposed [5-6].

Stressful circumstances have been found to be linked with psychological disturbances among this target group on account of undesirability associated with the change [7]. Perceived stress, which reflects appraisal of these stressful circumstances [8], has been found to be a significant associate of perceived health and mental well-being in some studies [9-10]. In a research conducted on university-going students in Barbados, researchers found an inverse association between perceived stress and life satisfaction [11], an important aspect of well-being [12]. Additionally, they found that students experienced dissatisfaction on account of factors such as on-campus facilities, financial security, job situation, and quality of academic instruction.

The current study looks into the concept of perceived stress among college students and its association with life satisfaction. Based on the literature, it was hypothesized that: 
1. Perceived stress will demonstrate a significant negative correlation with overall life satisfaction.

2. Perceived stress will demonstrate a significant negative correlation with domain-specific life satisfaction.

\section{METHODOLOGY}

\section{Sample Description}

Data were collected from 50 undergraduate students from different colleges in the metropolitan city of Mumbai, whose average age was 19.92 years $(\mathrm{SD}=1.16)$. The sample consisted of 6 males $(12.0 \%)$ and 43 females (86.0\%); gender of one participant was unknown. With respect to religion, the break-up was as follows: Hindus (66.0\%), Muslims (22.0\%), Jains (6.0\%), and Christians (6.0\%). With respect to annual family income (in INR), the break-up was as follows: below or equal to 2,00,000 (14.0\%), 2,00,001 to $5,00,000(22.0 \%), 5,00,001$ to $8,00,000(14.0 \%), 8,00,001$ to $12,00,000(16.0 \%)$ and above $12,00,000$ $(34.0 \%)$.

\section{Measures}

This section focuses on measures used in the current study to assess perceived stress and life satisfaction.

1. Demographic sheet involved responding about age, gender, religion, and annual family income.

2. Perceived stress was evaluated using the Perceived Stress Scale (PSS-4) [13], a 4-item questionnaire which requires respondents to assess "the degree to which situations in one's life are appraised as stressful" [13]. Participants are required to indicate the frequency of one's feelings and thoughts in the last month $(0=$ Never to $4=$ very often $)$ on a 5 -point Likert scale. The scores range from 0-16 with higher scores indicating higher levels of stress. In the current study, the Cronbach's alpha value of .806 was obtained for this scale.

3. Life satisfaction was measured using Satisfaction with Life Scale (SWLS) [14], a generic measure of life satisfaction, consists of 5 items which are expected to be responded on a 7-point rating scale ( $1=$ Strongly Disagree to $7=$ Strongly Agree). The scores range from 5 to 35, with higher scores indicating greater life satisfaction. In the current study, the Cronbach's alpha value of .925 was obtained for this scale.

4. Additionally, adapted version of Chow's (2005) Satisfaction with Specific Aspects of Life (SSAL) [15] was used to measure domain-specific life satisfaction. The scores range from 19 to 95 , with higher scores indicating higher levels of domain-specific life satisfaction. In the current study, the Cronbach's alpha value of 0.946 was obtained for this scale.

The data was collected online from the undergraduate students after they indicated their approval to participate in the study.

\section{STATISTICAL ANALYSIS}

SPSS 16.0 was used to enter and code raw data. Basic descriptive statistics such as mean and standard deviation were calculated for all the relevant variables. The relationships between these variables were examined using Pearson Product Moment Correlation.

\section{RESULTS \& DISCUSSION}

Descriptive statistics, including mean and standard deviation, for each of the relevant variables have been represented in Table 1. The relationships between PSS, SWLS, and SSAL, as measured using Pearson Product Moment Correlation, have been represented in Table 2. From this table, it can be inferred that PSS demonstrated a significant negative relationship with both SWLS $(r=-0.85, p<0.01)$ and SSAL $(r=$ $-0.743, p<0.01)$. On the other hand, SWLS and SSAL were found to demonstrate a significant positive correlation $(r=0.863, p<0.01)$. The obtained findings are consistent with research findings, which indicate an inverse correlation between perceived stress and life satisfaction [11]. The study is nevertheless not without its own share of limitations. The sample size was small, making it difficult to generalize the 
obtained results to the larger population. Additionally, the study relied on the self-report questionnaires, which could have triggered a social desirability bias [16]. Future research can include a larger sample size and adopt a regression framework to understand the dynamics of the relationship between perceived stress and life satisfaction. Nevertheless, the study lays down crucial implications for mental health professionals to design appropriate mental health interventions for the target population.

The students in this sample were relatively young undergraduates, who are preparing to go into the job market. Thus, the need to secure a job would be foremost in the minds of the students. In addition, these findings can be useful to educators and campus administrators by sensitizing them to ways to improve student life and develop coping strategies for stress. In particular, campus administrators will need to pay more attention to the areas where students were most dissatisfied.

These areas included campus facilities and instructors' quality of teaching, which can influence students' satisfaction with life at the university. It may be argued that inadequate facilities and poor teaching can lead to low levels of life satisfaction at the campus, which can negatively impact on students' academic performance. Thus, university administrators need to look at ways to improve campus facilities and methods of teaching. For example, there can be greater use of electronic computer-assisted teaching and the creation of more comfortable classrooms. These findings are even more important for the development of education in small developing countries. We see that these countries have to struggle with limited resources to meet the needs of their constituents, and this problem can affect the delivery of quality education.

Given the increased number of students that are on campus, it is important to examine how this increase impacts on students' life satisfaction at this university. This is imperative, as an increase of students each semester creates pressure on existing facilities, both the physical plant and the human resource component which consists of academic and non-academic staff. This pressure is inevitably transferred to the student population

Table 1 - Descriptive Statistics: Mean and Standard Deviation

\begin{tabular}{|c|c|c|}
\hline Variable & Mean & Standard Deviation \\
\hline PSS & 5.58 & 3.70 \\
\hline SWLS & 24.90 & 8.16 \\
\hline SSAL & 71.20 & 15.58 \\
\hline
\end{tabular}

PSS $=$ Perceived Stress, SWLS $=$ Satisfaction with Life, SSAL $=$ Satisfaction with Specific Aspects of Life

Table 2 - Overall Correlations between Perceived Stress and Life Satisfaction

\begin{tabular}{|c|c|c|}
\hline & SWLS & SSAL \\
\hline PSS & $-0.85^{* *}$ & $-0.743^{\star *}$ \\
\hline SWLS & & $0.863^{* *}$ \\
\hline SSAL & & \\
\hline \multicolumn{2}{|c|}{$\left({ }^{* *} \mathrm{p}<0.01\right.$ significant $)$} \\
\end{tabular}

\section{REFERENCES}

1. Sax LJ, Astin AW, Korn WS, Mahoney KM. The American Freshman: National Norms for Fall 2000. Higher Education Research Institute, University of California, Los Angeles Graduate School of Education and Information, 3005 Moore Hall, Mailbox 951521, Los Angeles, CA 90095-1521; 2000.

2. Abouserie R. Sources and levels of stress in relation to locus of control and self esteem in university students. Educ Psychol 1994;14(3):323-30.

3. Ross SE, Niebling BC, Heckert TM. Sources of stress among college students. Soc Psychol 1999;61(5):841-6. 
4. Selye H. Stress without distress. New York. 1974.

5. Goodman E, McEwen BS, Dolan LM, Schafer-Kalkhoff T, Adler NE. Social disadvantage and adolescent stress. J Adolesc Health 2005;37(6):484-92.

6. Hudson SA, O' Regan J. Stress and the graduate psychology student. J Clin Psychol 1994;50(6):973-7.

7. Robotham D, Julian C. Stress and the higher education student: a critical review of the literature. J Higher Educn 2006;30(02):107-17.

8. Pruessner JC, Hellhammer DH, Kirschbaum C. Burnout, perceived stress, and cortisol responses to awakening. Psychosom Med 1999;61(2):197-204.

9. Leung DY, Lam TH, Chan SS. Three versions of Perceived Stress Scale: validation in a sample of Chinese cardiac patients who smoke. BMC Pub Health 2010;10(1):513.

10. Teh HC, Archer JA, Chang W, Chen SH. Mental well- being mediates the relationship between perceived stress and perceived health. Stress Health 2015;31(1):71-7.

11. Alleyne M, Alleyne P, Greenidge D. Life satisfaction and perceived stress among university students in Barbados. J Psychol Africa 2010;20(2):291-7.

12. Diener E, Ryan K. Subjective well-being: A general overview. South Afr J Psychol 2009;39(4):391-406.

13. Cohen S, Kamarck T, Mermelstein R. Perceived stress scale. Measuring stress: A guide for health and social scientists. 1994.

14. Diener ED, Emmons RA, Larsen RJ, Griffin S. The satisfaction with life scale. J Personal Assess1985;49(1):71-5.

15. Chow HP. Life satisfaction among university students in a Canadian prairie city: A multivariate analysis. Soc Indicators Res 2005;70(2):139-50.

16. Fischer R. Standardization to account for cross-cultural response bias: A classification of score adjustment procedures and review of research in JCCP. J Cross Cult Psychol 2004;35(3):263-82.

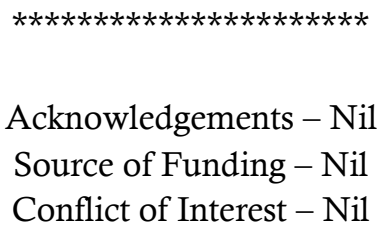

